\title{
An Economic Impact Of Maryland's Coastal Bays: A Goal Programming Approach
}

Dinesh K. Sharma, (Email: dksharma@mail.umes.edu), University of Maryland Eastern Shore Julius A. Alade, (Email: ajalade@mail.umes.edu), University of Maryland Eastern Shore Emmanuel T. Acquah, University of Maryland Eastern Shore

\begin{abstract}
The purpose of this paper is to present a lexicographic goal programming (LGP) model to assess fishery management and related activities and their economic impact on Maryland's Coastal Bays. The LGP model is designed to illustrate how LGP can be used as an aid to solving fishery management and related activities with multiple objectives. The technique allows us to find the optimal solution, based on the priorities of the goals in a decision-making environment. In this study, we have used LGP to examine a set of goals and objectives as they relate to the socioeconomic significance of fishery management in Maryland's Coastal Bays.
\end{abstract}

\section{INTRODUCTION}

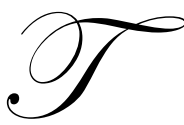

he need to balance users' interests with policy considerations that place emphasis on environmental issues as they relate to community development, fishery management (i.e., fishery capital, fish stocks, etc.), economic and ecological environments, and other socioeconomic dimensions poses difficult challenges in fisheries studies. Among the major challenges faced in fisheries management studies are: (1) the many conflicting goals and objectives that are frequently encountered by fishery managers and (2) the wide variety of socioeconomic factors that impact on the validity and effectiveness of regulatory instruments (Alade, Sharma and May, 2003; Charles, 1988). Besides, the management of fisheries and fishery systems is more complicated and intricate because of the explicit or implicit interactions among social, economic, biological, environmental, and regulatory components that involve fishermen and fishing communities.

Among the considerations lying within fishery socioeconomics' framework are distributional issues, labor market structure, social and opportunity costs, fishing community dynamics, and fishermen decision-making processes (Charles, 1988; Anderson, 1997; Fricke, 1985; Panayotou, 1985). In the study of fishery management, socioeconomic factors play a major role. In this paper, "fishery socioeconomics" will be used to connote aspects of the fishery system in which human and social elements influence fishery objectives and economic activity (Alade, Sharma and May, 2003). Significant among the major important goals identified in the study of fisheries development are increases in production, employment and fishermen's incomes, industry diversification, and skills development (Lawson, 1984; Charles, 1988). Other goals according to the United Nations Food and Agriculture Organization report (FAO 1983) classification are resource maintenance, economic performance, and equity or social needs. Similarly, the study by Emmerson (1980) proposed that conservation, fishery production or productivity, and income distribution are important goals in fisheries management.

In operations research (OR), several approaches have been developed to deal with multiple criteria decisionmaking (MCDM). A good review of the applications of MCDM techniques to fisheries management can be found in Mardle and Pascoe (1999). Everitt et al. (1978) applied goal programming (GP) for policy management of the salmon fishery with the impact of a large hydroelectric development program in the region of Skeena River. Amble (1981) presented weighted goal programming (WGP) to analyze the fleet structure of a local fleet for the multi-species. The model includes yearly catch, monthly fish deliveries, monthly employment, income, etc., in the Northern Norway. Weithman and Ebert (1981) also used WGP for fishery management to define a stock management plan for a three species of trout fishery in Lake Taneycomo. Sandiford (1986) and Drynan and Sandiford (1985) examined the use of 
WGP to the Scottish inshore fishery resource allocation. Stewart (1988) developed an interactive decision support system which consists of three methods such as interactive multiple GP, interactive sequential GP, and STEP method to formulate South African pelagic fishery quota determination. Also, Muthukude et al. (1991) developed WGP for fisheries development in Sri Lanka. Their model includes boat numbers, crew training, income, etc. Weerasooriya et al. (1992) also used GP to maximize catch, maximize internal rate of return, and maximize the number of vessels in Sri Lanka. Recent applications include the bi-level and bi-criterion programming model of Hawaii's multi-fisheries by Leung et al. (1999) and the WGP model of the UK component of the English Channel fishery by Pascoe and Mardle (2001). In the model by Leung et al. (1999), trade-offs between maximizing economic profits and maximizing recreational experiences were investigated. Pascoe and Mardle (2001) presented a multi-objective GP model of the English Channel multi-species, multi-gear fisheries to estimate the optimal fleet size and configuration from both a multi-objective and profit-maximizing. The model is used to derive the fleet configuration, which is consistent with the economic, employment, and distributional objectives of the Common Fisheries Policy of the European Union.

In literature, most of fishery related studies have used conventional lexicographic goal programming (LGP) model for the fishery planning problem and the solution under the decision-maker's priority structure is considered as the optimal solution. However, in different complex decision-making situations, the desired solution may not be acceptable under the imposed priority structure; that is, a better solution is always expected for which a number of priority structures may be considered (Steuer, 1986; Sharma et al., 2003).

In this paper, we present a LGP model to assess fishery management and related activities and their economic impact on Maryland's Coastal Bays. The LGP model is designed to illustrate how LGP can be used as an aid to solving fishery management and related activities with multiple objectives. The technique allows us to find the optimal solution, based on the priorities of the goals in a decision-making environment. In this study, we have used LGP to examine a set of goals and objectives as they relate to the socioeconomic significance of fishery management in Maryland's Coastal Bays. A sensitivity analysis on the priority structure of the goals is performed to obtain all feasible solutions. The model uses the Euclidean distance method to measure distances of all feasible solutions from the identified ideal solution. The optimal solution is determined based on minimum distance between the ideal solution and other possible solutions of the problem.

\section{GOAL PROGRAMMING MODEL DEVELOPMENT}

The LGP model has been described in detail by several authors (Ijiri, 1965; Lee, 1972; Ignizio, 1976; and Olson, 1984). The general model of the LGP can be written as:

$$
\begin{array}{ll}
\text { Find } \bar{X}\left(X_{1}, X_{2}, X_{3}, \ldots . ., X_{\mathrm{n}}\right) \text { so as to } \\
\text { Minimize } & P_{I}\left(w_{i 1}{ }^{+} d_{i 1}{ }^{+}+w_{i 1}{ }^{-} d_{i 1}{ }^{-}\right), \\
\text {Minimize } & P_{2}\left(w_{i 2}{ }^{+} d_{i 2}{ }^{+}+w_{i 2}{ }^{-} d_{i 2}{ }^{-}\right),
\end{array}
$$

Minimize $\quad P_{k}\left(w_{i \mathrm{k}}{ }^{+} d_{i \mathrm{k}}{ }^{+}+w_{i \mathrm{k}}{ }^{-} d_{i \mathrm{k}}{ }^{-}\right)$,

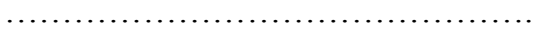

Minimize

$$
P_{K}\left(w_{i \mathrm{~K}}{ }^{+} d_{i \mathrm{~K}}{ }^{+}+w_{i \mathrm{~K}}{ }^{-} d_{i \mathrm{~K}}{ }^{-}\right), \text {where } i=1,2,3, \ldots, \mathrm{m}
$$

Subject to,

$$
\begin{aligned}
& f_{i}(\bar{X})+d_{i}^{-}-d_{i}^{+}=b_{i}, \\
& d_{i}^{-}, d_{i}^{+}, \bar{X} \geq 0 \text { and } d_{i}^{-} \cdot d_{i}^{+}=0 \text { for } i=1,2,3, \ldots, \mathrm{m} ; \mathrm{k}=1,2,3, \ldots, \mathrm{K} \\
& \text { where } \bar{X}=\text { vector of } \mathrm{n} \text { decision variables. }
\end{aligned}
$$


$P_{k}=k^{\text {th }}$ priority factor as assigned to the set of goals, $1 \leq k \leq \mathrm{K} \leq \mathrm{m}$

Also $P_{i} \gg \gg \gg \gg>P_{i+1} ; \quad 1 \leq i \leq \mathrm{K}$

$f_{i}(\bar{X})=$ constant function for $i^{\text {th }}$ goal

$d_{i k}{ }^{-} \quad=$ under-achievement from the $i^{\text {th }}$ goal level $b_{i}$, at the priority level $P_{k}$

$d_{i k}{ }^{+} \quad=$ under-achievement from the $i^{\text {th }}$ goal level $b_{i}$, at the priority level $P_{k}$

$w_{i k}{ }^{+}$and $w_{i k}{ }^{-}(\geq 0)$ are numerical weights associated with the deviational variables $d_{i k}{ }^{-}$and $d_{i k}{ }^{+}$respectively

where $d_{i k}{ }^{-}$and $d_{i k}{ }^{+}$are renamed for the convenience of actual deviational variables $d_{i}{ }^{-}$and $d_{i}^{+}$respectively.

To formulate the LGP model of the problem, the following notations are defined:

\section{Indices}

$i \quad$ index for the activity $i \in\{1,2, \ldots, I\}$ on Coastal Bays..

$j \quad$ index for the sub activity $j \in\{1,2, \ldots, \mathrm{J}\}$ of activity $i$ on Coastal Bays.

\section{Variables and Parameters}

$X_{i j}=$ Number of days for activity $i$ and sub activity $j$.

$E_{i j}=$ Expenditure per day for activity $i$ and sub activity $j$.

$R_{i j}=$ Revenue for activity $i$ and sub activity $j$.

$A D_{i j}=$ Activity days for activity $i$ and sub activity $j$.

$T E=$ Total expenditure from all activities.

$T R=$ Total revenue from all activities.

$T A D=$ Total activity days.

$r_{i j}=$ Revenue per day for activity $i$ and sub activity $j$.

$c_{i j}=$ Cost per day for activity $i$ and sub activity $j$.

\section{The Goals}

The goals set in order of importance in the decision making environment can be defined as follows:

(i) maximize activity days

(ii) minimize expenditure

(iii) maximize revenue

\section{Constraints}

To formulate the LGP model, the following goal constraints appear in the model:

(i) Total expenditure from all activities on Coastal Bays can be written as: 


$$
\sum_{i=1}^{I} \sum_{j=1}^{J} c_{i j} X_{i j}+d_{T E}^{-}-d_{T E}^{+}=T E
$$

(ii) Expenditure from sub activity on Coastal Bays can be expressed as:

$$
c_{i j} X_{i j}+d_{E}^{-}-d_{E}^{+}=E_{i j}, \quad \forall i \text { and } j
$$

(iii) Total revenue from all activities on Coastal Bays can be written as:

$$
\sum_{i=1}^{I} \sum_{j=1}^{J} r_{i j} X_{i j}+d_{T R}^{-}-d_{T R}^{+}=T R
$$

(iv) Revenue from sub activity on Coastal Bays can be expressed as:

$$
r_{i j} X_{i j}+d_{R}^{-}-d_{R}^{+}=R_{i j}, \quad \forall i \text { and } j
$$

(v) Total activity days (TAD) from all activities on Coastal Bays can be written as:

$$
\sum_{i=1}^{I} \sum_{j=1}^{J} X_{i j}+d_{T A D}^{-}-d_{T A D}^{+}=T A D
$$

(vi) Activity days from sub activity on Coastal Bays can be expressed as:

$$
X_{i j}+d_{A D}^{-}-d_{A D}^{+}=A D_{i j}, \quad \forall i \text { and } j
$$

\section{Sensitivity Analysis On Priority Structure}

The objective function of the model is the inclusion of deviational variables with their respective weights in the decision-making environment in different priority levels. The performance of the model depends on the appropriate priority structure of the model. To select the appropriate priority structure of the model, sensitivity analysis on all priorities is performed. The ideal solution is then calculated from all different solutions obtained from different priority structures. The Euclidean distance function is used to measure distances of all possible solutions from the ideal solution. The distance can be measured as follows:

In the model, $\mathrm{K}$ priorities have been considered. From a structure of $\mathrm{K}$ priorities, $\mathrm{K}$ ! priority structures can be derived, out of which decision-makers may consider $\mathrm{N}$ number of priority structures that are relevant to the study region. Therefore, maximum $\mathrm{N}$ different solutions can be obtained from the problem with $\mathrm{N}$ set of different priority structures.

Let $\left\{\left[X_{i j}\right]^{n}\right\}, i=1,2, \ldots, I ; j=1,2, . ., J$ for each $n=1,2,3, \ldots \ldots, N$

The ideal solution can be identified as (Cohon 1978):

$\left[X_{\mathrm{ij}}\right]^{*}, \mathrm{i}=1,2, \ldots, \mathrm{I} ; \mathrm{j}=1,2, \ldots, \mathrm{J}=$ Maximum $\left\{\left[X_{\mathrm{ij}}\right]^{\mathrm{n}}\right\}, \mathrm{i}=1,2, \ldots, \mathrm{I} ; \mathrm{j}=1,2, \ldots, \mathrm{J}$ for each $\mathrm{n}=1,2, \ldots, \mathrm{N}$

The Euclidean distance $\left\{D_{n}\right\}, n=1,2, . ., N$, of each solution $\left\{\left[X_{\mathrm{ij}}\right]^{\mathrm{n}}\right\}, \mathrm{i}=1,2, \ldots, \mathrm{I} ; \mathrm{j}=1,2, \ldots, \mathrm{J}$ from the ideal solution $\left\{\left[X_{\mathrm{ij}}\right]^{*}\right\}, \mathrm{i}=1,2, \ldots, \mathrm{I} ; \mathrm{j}=1,2, \ldots, \mathrm{J}$ can be presented as: 
$\mathrm{D}_{\mathrm{n}}=\sqrt{ } \sum\left(\left[X_{\mathrm{ij}}\right]^{*}-\left[X_{\mathrm{ij}}\right]^{\mathrm{n}}\right)^{2}, \mathrm{n}=1,2, \ldots, \mathrm{N}$

In realistic situations, the ideal solution may not be achieved (Cohon, 1978). The solution set, which is closest to the ideal solution, will be the best possible solution and the associate priority structure will be the best structure in the decision-making environment.

To demonstrate the usefulness of the proposed LGP model, the following case study has been considered.

\section{CASE STUDY}

The Coastal Bays of Maryland which consist of Assawoman, Isle of Wight, Newport, Sinepuxent and Chincoteague Bays provide vital natural resources to the environment and to the economy of the State of Maryland and Worcester County. The area supports a permanent population of over 40,000 and annually attracts as many as ten million visitors. Maryland's Coastal Bays are enormous environmental and economic resources to the State and region. These economic resources are dependent to a large extent on the natural environment that supports the region's largest industry, tourism, and a relatively small permanent population (Greeley-Polhemus, 2001).

The coastal bays watershed supports numerous rare and threatened plant and animal species, forests and wetlands vital to migratory songbirds and waterfowl, and numerous important commercial and recreational fin and shellfish species. From recreational and commercial perspectives, the coastal bays are an asset to the entire midAtlantic region. Apart from the year-around population, which is increasing at a very fast pace annually, the coastal bays watershed attracts more than 10 million vacationers who spend in excess of $\$ 2.1$ billion each year. Commercial fishing, recreational fishing and boating are also key contributors to the region's economy (Alade, Sharma and May, 2003; Greeley-Polhemus, 2001). County, State and Federal government agencies all provide services in relation to the Coastal Bays. The County provides 10 public boat-launching ramps, 7 marinas with 574 boat slips, 3 public parks and associated services including water, wastewater and trash disposal. There are also two health clinics provided by the County. These facilities and services are directly related to the Bays. However, it could be assumed that all the Bayrelated facility development and County services that are provided to support the Bay communities would not have possibly been developed without the Bays. A summary of data is given in Tables 1 and 2 .

Table 1: Direct Expenditures For Recreational Participation (2000)

\begin{tabular}{|l|c|c|c|}
\hline \multicolumn{1}{|c|}{ Activity } & Cost per Day (\$) & Activity Days & Total Expenditure (\$) \\
\hline 1. Sightseeing & 6.15 & $3,478,200$ & $21,400,000$ \\
\hline 2. Wildlife Observation & 8.82 & $3,035,500$ & $20,700,000$ \\
\hline 3. Swimming & 6.04 & 316,200 & $1,910,000$ \\
\hline 4. Fishing, etc. & 6.54 & 189,700 & $1,240,000$ \\
\hline 5. Camping & 17.72 & 360,000 \\
\hline 6. Hunting & 33.34 & 9,000 & 300,000 \\
\hline 7. Motor boating & 22.66 & 169,000 & $3,830,000$ \\
\hline 8. Personal Watercraft (Jet skiing) & 38.32 & 44,100 & $1,690,000$ \\
\hline 9. Canoeing, Kayaking or Wind-Surfing & 39.72 & 8,800 & 350,000 \\
\hline 10. Food & 6.33 & $6,324,400$ & $40,000,000$ \\
\hline 11. Lodging & 11.15 & $4,484,000$ & $50,000,000$ \\
\hline 12. Transportation & 3.79 & $6,324,000$ & $24,000,000$ \\
\hline Total & \multicolumn{3}{|c|}{} \\
\hline
\end{tabular}


Table 2: Total Commercial Value Of Rentals (2000)

\begin{tabular}{|l|c|c|c|}
\hline \multicolumn{1}{|c|}{ Activity } & Revenue per day (\$) & Activity Days & Total Revenue (\$) \\
\hline 1. Motorboats & 20 & 72,000 & $1,440,000$ \\
\hline 2. Parasailing & 55 & 12,960 & 712,800 \\
\hline 3. Sailboats & 35 & 8,640 & 302,400 \\
\hline 4. Personal Watercraft (Jet skis) & 35 & 28,800 & $1,000,000$ \\
\hline 5. Canoeing Kayaking and Wind-Surfing & 35 & 3,240 & 113,400 \\
\hline 6. Eco-Tours & 12 & 12,150 & 145,800 \\
\hline 7. Dolphin Watch & 126 & 1,080 & 136,080 \\
\hline 8. Speedboat Tours & 8 & 70,200 & 561,600 \\
\hline 9. Day and Evening Cruises & 5 & 137,700 & 688,500 \\
\hline 10. "Head-Boat" Fishing & 20 & 106,800 & $2,136,000$ \\
\hline Total & \multicolumn{3}{|}{} \\
\hline
\end{tabular}

\section{The Priority Structure}

In this study, three priority levels are addressed to include the goal constraints according to their importance of achievement in the model. The priority structure of the problem can be defined as follows:

- $\quad$ Priority 1: Minimize expenditure

- $\quad$ Priority 2: Maximize revenue

- $\quad$ Priority 3: Maximize activity days

For the data given in Tables 1 and 2, the GP problem is formulated as follows:

$\underline{\text { Expenditure Goal }}$

$$
\begin{aligned}
& 6.15 \mathrm{X}_{1,1}+8.82 \mathrm{X}_{1,2}+6.04 \mathrm{X}_{1,3}+6.54 \mathrm{X}_{1,4}+17.72 \mathrm{X}_{1,5}+33.34 \mathrm{X}_{1,6}+22.66 \mathrm{X}_{1,7}+ \\
& 38.32 \mathrm{X}_{1,8}+39.72 \mathrm{X}_{1,9}+6.33 \mathrm{X}_{1,10}+11.15 \mathrm{X}_{1,11}+3.79 \mathrm{X}_{1,12}+d_{1}^{-}-d_{1}^{+}=165,980,000 \\
& 6.15 \mathrm{X}_{1,1}+d_{2}^{-}-d_{2}^{+}=21400000 \\
& 8.82 \mathrm{X}_{1,2}+d_{3}^{-}-d_{3}^{+}=20700000 \\
& 6.04 \mathrm{X}_{1,3}+d_{4}^{-}-d_{4}^{+}=1910000 \\
& 6.54 \mathrm{X}_{1,4}+d_{5}^{-}-d_{5}^{+}=1240000 \\
& 17.72 \mathrm{X}_{1,5}+d_{6}^{-}-d_{6}^{+}=560000 \\
& 33.34 \mathrm{X}_{1,6}+d_{7}^{-}-d_{7}^{+}=300000 \\
& 22.66 \mathrm{X}_{1,7}+d_{8}^{-}-d_{8}^{+}=3830000 \\
& 38.32 \mathrm{X}_{1,8}+d_{9}^{-}-d_{9}^{+}=1690000 \\
& 39.72 \mathrm{X}_{1,9}+d_{10}^{-}-d_{10}^{+}=350000 \\
& 6.33 \mathrm{X}_{1,10}+d_{11}^{-}-d_{11}^{+}=40000000 \\
& 11.15 \mathrm{X}_{1,11}+d_{12}^{-}-d_{12}^{+}=24000000
\end{aligned}
$$




$$
3.79 \mathrm{X}_{1,12}+d_{13}^{-}-d_{13}^{+}=1440000
$$

$\underline{\text { Revenue Goal }}$

$$
\begin{aligned}
& 20 \mathrm{X}_{2,1}+55 \mathrm{X}_{2,2}+35 \mathrm{X}_{2,3}+35 \mathrm{X}_{2,4}+35 \mathrm{X}_{2,5}+12 \mathrm{X}_{2,6}+126 \mathrm{X}_{2,7}+8 \mathrm{X}_{2,8}+5 \mathrm{X}_{2,9}+ \\
& 20 \mathrm{X}_{2,10}+d_{14}^{-}-d_{14}^{+}=7,196,580 \\
& 20 \mathrm{X}_{2,1}+d_{15}^{-}-d_{15}^{+}=1440000 \\
& 55 \mathrm{X}_{2,2}+d_{16}^{-}-d_{16}^{+}=712800 \\
& 35 \mathrm{X}_{2,3}+d_{17}^{-}-d_{17}^{+}=302400 \\
& 35 \mathrm{X}_{2,4}+d_{18}^{-}-d_{18}^{+}=1000000 \\
& 35 \mathrm{X}_{2,5}+d_{19}^{-}-d_{19}^{+}=113400 \\
& 12 \mathrm{X}_{2,6}+d_{20}^{-}-d_{20}^{+}=145800 \\
& 126 \mathrm{X}_{2,7}+d_{21}^{-}-d_{21}^{+}=136080 \\
& 8 \mathrm{X}_{2,8}+d_{22}^{-}-d_{22}^{+}=561600 \\
& 5 \mathrm{X}_{2,9}+d_{23}^{-}-d_{23}^{+}=688500 \\
& 20 \mathrm{X}_{2,10}+d_{24}^{-}-d_{24}^{+}=2136000
\end{aligned}
$$

Activity Days Goal

$$
\begin{aligned}
& \mathrm{X}_{1,1}+\mathrm{X}_{1,2}+\mathrm{X}_{1,3}+\mathrm{X}_{1,4}+\mathrm{X}_{1,5}+\mathrm{X}_{1,6}+\mathrm{X}_{1,7}+\mathrm{X}_{1,8}+\mathrm{X}_{1,9}+\mathrm{X}_{1,10}+\mathrm{X}_{1,11}+\mathrm{X}_{1,12}+\mathrm{X}_{2,1}+ \\
& \mathrm{X}_{2,2}+\mathrm{X}_{2,3}+\mathrm{X}_{2,4}+\mathrm{X}_{2,5}+\mathrm{X}_{2,6}+\mathrm{X}_{2,7}+\mathrm{X}_{2,8}+\mathrm{X}_{2,9}+\mathrm{X}_{2,10}+d_{25}^{-}-d_{25}^{+}=24868070 \\
& \mathrm{X}_{1,1}+d_{26}^{-}-d_{26}^{+}=3478200 \\
& \mathrm{X}_{1,2}+d_{27}^{-}-d_{27}^{+}=3035500 \\
& \mathrm{X}_{1,3}+d_{28}^{-}-d_{28}^{+}=316200 \\
& \mathrm{X}_{1,4}+d_{29}^{-}-d_{29}^{+}=189700 \\
& \mathrm{X}_{1,5}+d_{30}^{-}-d_{30}^{+}=31600 \\
& \mathrm{X}_{1,6}+d_{31}^{-}-d_{31}^{+}=9000 \\
& \mathrm{X}_{1,7}+d_{32}^{-}-d_{32}^{+}=169000 \\
& \mathrm{X}_{1,8}+d_{33}^{-}-d_{33}^{+}=44100 \\
& \mathrm{X}_{1,9}+d_{34}^{-}-d_{34}^{+}=8800
\end{aligned}
$$




$$
\begin{aligned}
& \mathrm{X}_{1,10}+d_{35}^{-}-d_{35}^{+}=6324400 \\
& \mathrm{X}_{1,11}+d_{36}^{-}-d_{36}^{+}=4484000 \\
& \mathrm{X}_{1,12}+d_{37}^{-}-d_{37}^{+}=6324000 \\
& \mathrm{X}_{2,1}+d_{38}^{-}-d_{38}^{+}=72000 \\
& \mathrm{X}_{2,2}+d_{39}^{-}-d_{39}^{+}=12960 \\
& \mathrm{X}_{2,3}+d_{40}^{-}-d_{40}^{+}=8640 \\
& \mathrm{X}_{2,4}+d_{41}^{-}-d_{41}^{+}=28800 \\
& \mathrm{X}_{2,5}+d_{42}^{-}-d_{42}^{+}=3240 \\
& \mathrm{X}_{2,6}+d_{43}^{-}-d_{43}^{+}=12150 \\
& \mathrm{X}_{2,7}+d_{44}^{-}-d_{44}^{+}=1080 \\
& \mathrm{X}_{2,8}+d_{45}^{-}-d_{45}^{+}=70200 \\
& \mathrm{X}_{2,9}+d_{46}^{-}-d_{46}^{+}=137700 \\
& \mathrm{X}_{2,10}+d_{47}^{-}-d_{47}^{+}=106800
\end{aligned}
$$

\section{RESULTS}

The problem has been executed in a GP package, developed in Visual C++. The algorithm presented by Ignizio (1976) has been used to develop the GP package. In the problem, three priorities have been considered. The solution obtained for each 6 Runs are presented in Table 2. To determine the optimal solution, the distance of each solution set, from the ideal solution set, is calculated. The distance from the ideal solution is $(6421990,6421990$, $8967995,8967995,6421990,8967995)$. The minimum distance from the solutions to the ideal solution corresponds to Runs 1, 2 and 5. In this situation, any Run out of these three Runs can be selected for the decision making process. The solution of the problem indicates that priorities 1 and 2 are fully achieved. However, priority 3 is under achieved.

\section{CONCLUDING REMARKS}

The objective of this study is to present a LGP model to assess fishery management and related activities and their economic impact on Maryland's Coastal Bays. The Coastal Bays in Worcester County are important natural and economic resources. In addition to the natural habitat and living resources the Bays support, the Bays provide a setting for recreational activities and development. The model presented in this study and the consequent results could become an important factor in assessing similar scenarios and, more significantly, in helping to reassess the economic significance of Maryland's Coastal Bays. For policy analysis, the model and the outcome of the data generated presents a vital opportunity for setting policy guidelines with major consequences on the economic and ecological development of the coastal bay region. It is demonstrated in the study that the LGP approach is a superior technique over single objective criterion when multiple conflicting objectives are involved. The LGP model, which captures the essence of priority in decision making with special advantage over linear and other mathematical programming, provides the best possible solution subject to the model constraints and priority structure of the goals. 


\section{ACKNOWLEDGEMENT}

This paper was funded from the NOAA grant for the Living Marine Resource Cooperative Science Center (LMRCSC) project, University of Maryland Eastern Shore.

Table 3: Priorities And Corresponding Solutions

\begin{tabular}{|c|c|c|c|c|c|c|c|}
\hline Variable & $\begin{array}{c}\text { Run 1 } \\
\mathbf{P}_{\mathbf{1}} \mathbf{P}_{\mathbf{2}} \mathbf{P}_{\mathbf{3}} \\
\end{array}$ & $\begin{array}{l}\text { Run 2 } \\
\mathbf{P}_{2} \mathbf{P}_{1} \mathbf{P}_{3} \\
\end{array}$ & $\begin{array}{l}\text { Run 3 } \\
\mathbf{P}_{3} \mathbf{P}_{2} \mathbf{P}_{1} \\
\end{array}$ & $\begin{array}{c}\text { Run 4 } \\
\mathbf{P}_{3} \mathbf{P}_{1} \mathbf{P}_{2} \\
\end{array}$ & $\begin{array}{l}\text { Run 5 } \\
\mathbf{P}_{1} \mathbf{P}_{\mathbf{3}} \mathbf{P}_{\mathbf{2}} \\
\end{array}$ & $\begin{array}{l}\text { Run 6 } \\
\mathbf{P}_{2} \mathbf{P}_{3} \mathbf{P}_{1} \\
\end{array}$ & $\begin{array}{c}\text { Ideal } \\
\text { Solution }\end{array}$ \\
\hline $\mathrm{X} 1,1$ & 3479675 & 3479675 & 3478200 & 3478200 & 3479675 & 3478200 & 3479675 \\
\hline $\mathrm{X} 1,2$ & 2346939 & 2346939 & 3035500 & 3035500 & 2346939 & 3035500 & 3035500 \\
\hline $\mathrm{X} 1,3$ & 316225 & 316225 & 316200 & 316200 & 316225 & 316200 & 316225 \\
\hline $\mathrm{X} 1,4$ & 189603 & 189603 & 189700 & 189700 & 189603 & 189700 & 189700 \\
\hline $\mathrm{X} 1,5$ & 31603 & 31603 & 31600 & 31600 & 31603 & 31600 & 31603 \\
\hline $\mathrm{X} 1,6$ & 8998 & 8998 & 9000 & 9000 & 8998 & 9000 & 9000 \\
\hline $\mathrm{X} 1,7$ & 169020 & 169020 & 169000 & 169000 & 169020 & 169000 & 169020 \\
\hline $\mathrm{X} 1,8$ & 44102 & 44102 & 44100 & 44100 & 44102 & 44100 & 44102 \\
\hline $\mathrm{X} 1,9$ & 8812 & 8812 & 8800 & 8800 & 8812 & 8800 & 8812 \\
\hline $\mathrm{X} 1,10$ & 6319116 & 6319116 & 6324400 & 6324400 & 6319116 & 6324400 & 6324400 \\
\hline $\mathrm{X} 1,11$ & 2152467 & 2152467 & 4484000 & 4484000 & 2152467 & 4484000 & 4484000 \\
\hline $\mathrm{X} 1,12$ & 379947 & 379947 & 6324000 & 6324000 & 379947 & 6324000 & 6324000 \\
\hline $\mathrm{X} 2,1$ & 72000 & 72000 & 72000 & 72000 & 72000 & 72000 & 72000 \\
\hline $\mathrm{X} 2,2$ & 12960 & 12960 & 12960 & 12960 & 12960 & 12960 & 12960 \\
\hline $\mathrm{X} 2,3$ & 8640 & 8640 & 8640 & 8640 & 8640 & 8640 & 8640 \\
\hline $\mathrm{X} 2,4$ & 28800 & 28800 & 28800 & 28800 & 28800 & 28800 & 28800 \\
\hline $\mathrm{X} 2,5$ & 3240 & 3240 & 3240 & 3240 & 3240 & 3240 & 3240 \\
\hline $\mathrm{X} 2,6$ & 12150 & 12150 & 12150 & 12150 & 12150 & 12150 & 12150 \\
\hline $\mathrm{X} 2,7$ & 1080 & 1080 & 1080 & 1080 & 1080 & 1080 & 1080 \\
\hline $\mathrm{X} 2,8$ & 70200 & 70200 & 70200 & 70200 & 70200 & 70200 & 70200 \\
\hline $\mathrm{X} 2,9$ & 9105695 & 9105695 & 137700 & 137700 & 9105695 & 137700 & 9105695 \\
\hline $\mathrm{X} 2,10$ & 106800 & 106800 & 106800 & 106800 & 106800 & 106800 & 106800 \\
\hline
\end{tabular}

\section{REFERENCES}

1. Alade, J. A., Sharma, D. K., and May, E. (2003). A Multi-criteria Decision Making Approach to Socioeconomic Impact of Fish Resource Utilization in Maryland Coastal Bays Region. Review of Business Research, 1(1), 238-246.

2. Amble, A. (1981). Multi-objective optimization of a local fishing fleet - a goal programming approach. Applied Operations Research in Fishing, Plenum Press, New York, 1981.

3. Anderson, R., ed. (1997). North Atlantic Marine Cultures: Anthropological Essays on Changing Adaptations. The Hague, Mouton.

4. Charles, A. T. (1988). Fishery Socioeconomics: A Survey. Land Economics, 64(3), 276-295.

5. Cohon, J. L. (1978). Multi-objective programming and planning. Academic Press, New York.

6. Drynan, R. G. and Sandiford, F. (1985). Incorporating economic objectives in goal programming for fishery management. Marine Resource Economics, 2, 175-195.

7. Emmerson, D. K. (1980). Rethinking Artisanal Fisheries Development: Western Concepts, Asian Experiences, World Bank Working Paper No. 423.

8. $\quad$ Everitt, R. R., Sonntag, N. C., Puterman, M. L., and Whalen, P. (1978). A mathematical programming model for the management of a renewable resource system: the Kemano II development project. Journal of the Fisheries Research Board of Canada, 35(2), 235-246. 
9. FAO (1983). Report of the Expert Consultation on the Regulation of Fishing Effort (Fishing Mortality). FAO Fisheries Report, No. 289, Rome.

10. Fricke, P. (1985). Use of Sociological Data in the Allocation of Common Property Resources. Marine Policy, 9, 39-52.

11. Greeley-Polhemus Group, Inc. (2001). An Assessment of the Economic Value of the Coastal Bays' Natural Resources to the Economy of Worcester County, Maryland.

12. Ignizio, J. P. (1976). Goal Programming and Extensions. Heath, Lexington, Massachusetts.

13. Ijiri, Y. (1965). Management goals and accounting for control. North Holland, Amsterdam.

14. Lawson, R. (1984). Economics of Fisheries Development. London: Frances Pinter Publishers.

15. Lee, S. M. (1972). Goal Programming for Decision Analysis. Auerbach, Philadelphia, PA.

16. Leung, P., Pan, M., Ji, F., Nakamoto, S. T., and Pooley, S. G. (1999). A bilevel and bi-criterion programming model of Hawaii's multi-fisheries. Ocean-Scale Management of Pelagic Fisheries: Economic and Regulatory Issues, JIMAR 99-321. Joint Institute of Marine and Atmospheric Research, University of Hawaii at Manoa, 41-63.

17. Mardle, S. and Pascoe, S. (1999). A Review of applications of multiple-criteria decision-making techniques to fisheries. Marine Resource Economics, 14 (1), 41-63.

18. Muthukude, P., Novak, J. L., and Jolly, C. (1991). Goal programming evaluation of fisheries development plans for Sri Lanka's coastal fishing fleet. Fisheries Research, 12, 325-339.

19. Olson, D. L. (1984). Comparison for four Goal Programming Algorithm. Journal of Operational Research Society, 35(4), 347-354.

20. Panayotou, T., ed. (1985). Small-scale Fisheries in Asia: Socioeconomic Analysis and Policy. Ottawa: International Development Center.

21. Pascoe, S. and Mardle, S. (2001). Optimal fleet size in the English Channel: a multi-objective programming approach. European Review of Agricultural Economics, 28(2), 161-185.

22. Sandiford, F. (1986). An analysis of multi-objective decision making for the Scottish inshore fishery. Journal of Agricultural Economics, 37(2), 207-219.

23. Sharma, D. K., Ghosh, D., and Alade, A. J. (2003). Management decision-making for sugar cane fertilizer mix problems through goal programming. Journal of Applied Mathematics and Computing, 13(1-2), 323334.

24. Steuer, R. E. (1986). Multiple criteria optimization theory, computation and application. Wiley, New York.

25. Stewart, T. J. (1988). Experience with prototype multicriteria decision support systems for pelagic fish quota determination. Naval Research Logistics, 35, 719-731.

26. Weerasooriya, K. T., Hills, W., and Sen, P. (1992). The selection of fishing vessel fleet operations using a multiple criteria optimization method, Maritime Policy Management, 19(1), 41-54.

27. Weithman, A. S. and Ebert, R. J. (1981). Goal programming to assist in decision making. Fisheries, 6(1), 58. 